\section{Current Approaches for Integrating Responsible and Ethical Conduct of Research (RECR) Education into Course-based Undergraduate Research Experiences: A National Assessment}

\author{
Laura A. Diaz-Martinez, ${ }^{\text {} \ddagger \S}$ Aimee A. Hernandez, ${ }^{\ddagger}$ Christina E. D'Arcy, ${ }^{\ddagger}$

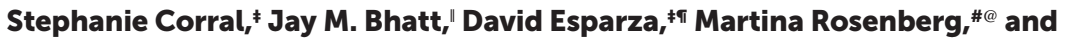 \\ Jeffrey T. Olimpo** \\ ${ }^{\dagger}$ Campus Office of Undergraduate Research Initiatives (COURI) and "Department of Biological \\ Sciences, University of Texas at El Paso, El Paso, TX 79968; \$ Department of Biology (current \\ address), Gonzaga University, Spokane, WA 99258; "Department of Pharmacology, School of \\ Medicine, Creighton University, Omaha, NE 68178; 'Department of Ecology and Evolutionary \\ Biology (current address), Cornell University, Ithaca, NY 14850; "Department of Biochemistry \\ and Molecular Biology, University of New Mexico, Albuquerque, NM 87131
}

\begin{abstract}
Course-based undergraduate research experiences (CUREs), which often engage students as early as freshman year, have become increasingly common in biology curricula. While many studies have highlighted the benefits of CUREs, little attention has been paid to responsible and ethical conduct of research (RECR) education in such contexts. Given this observation, we adopted a mixed methods approach to explore the extent to which RECR education is being implemented and assessed in biological sciences CUREs nationwide. Survey and semistructured interview data show a general awareness of the importance of incorporating RECR education into CUREs, with all respondents addressing at least one RECR topic in their courses. However, integration of RECR education within the CURE environment primarily focuses on the application of RECR during research practice, often takes the form of corrective measures, and appears to be rarely assessed. Participants reported lack of time and materials as the main barriers to purposeful inclusion of RECR education within their courses. These results underscore a need for the CURE community to develop resources and effective models to integrate RECR education into biology CUREs.
\end{abstract}

\section{INTRODUCTION}

Responsible and ethical conduct of research (RECR) is critical to promoting the integrity of the scientific enterprise. This is exemplified by the emphasis institutions, scientific communities, and funding agencies place on adherence to RECR standards (National Institutes of Health, 1989, 2009; America COMPETES Act, 2007; National Academy of Sciences, 2009; Universities UK, 2012; ALLEA, 2017; National Health and Medical Research Council, 2018). By extension, globalization of the scientific endeavor has led to international recognition of the importance of RECR and has spawned efforts to provide a unified universal standard, as illustrated by the drafting of the Singapore Statement (Resnik and Shamoo, 2011). Collectively, these efforts have identified core principles (e.g., honesty, fairness, objectivity) that inform responsible and ethical conduct of research. These principles guide scientific practice, facilitate effective collaboration, promote researcher accountability, and establish a foundation upon which research may continue to serve the public good.
Derek Braun, Monitoring Editor

Submitted Aug 10, 2020; Revised May 5, 2021; Accepted May 11, 2021

CBE Life Sci Educ September 1, 2021 20:ar38 DOI:10.1187/cbe.20-08-0179

๑Current address: Center for Excellence in Teaching and Learning, University of Connecticut, Storrs, CT 06269.

*Address correspondence to: Jeffrey T. Olimpo (jtolimpo@utep.edu)

(c) 2021 L. A. Diaz-Martinez et al. CBE-Life Sciences Education (๑) 2021 The American Society for Cell Biology. This article is distributed by The American Society for Cell Biology under license from the author(s). It is available to the public under an Attribution-Noncommercial-Share Alike 3.0 Unported Creative Commons License (http://creativecommons.org/licenses/ by-nc-sa/3.0).

"ASCB®" and "The American Society for Cell Biology ${ }^{\circledR}$ " are registered trademarks of The American Society for Cell Biology. 
To actualize these ideals, the National Science Foundation (NSF), the National Institutes of Health (NIH), and the Public Health Service developed policies to encourage formalized RECR education of research trainees (Health and Human Services Department, 2000; Steneck and Bulger, 2007). These policies resulted in the creation of programs and pedagogical tools for RECR education, including the widely used Collaborative Institutional Training Initiative (CITI; Braunschweiger and Goodman, 2007). In response, RECR education of emerging scientists (e.g., undergraduate and graduate students, postbaccalaureate scholars) in the United States shifted from purely mentor-based training to a combination of mentoring by senior researchers and formalized training mandated by the funding agencies (National Institutes of Health, 1989, 2009; America COMPETES Act, 2007; National Academy of Sciences, 2009). Yet, the specific educational approach(es) employed to deliver federally-mandated instruction varies by institution. A study of NSF-funded programs revealed that a majority $(82 \%)$ of research-intensive institutions require trainees to complete at least one online training, while other institutions (17\%) have adopted more comprehensive approaches that involve in-person workshops or courses (Phillips et al., 2018). Additionally, many institutions have extended RECR education by mandating that non-federally funded trainees also participate in RECR instruction (Resnik and Dinse, 2012). In general, however, these efforts have focused on the education of postbaccalaureate scholars (Resnik and Dinse, 2012; Phillips et al., 2018).

Comparatively, undergraduate research trainees often have minimal access or exposure to RECR education, and its effectiveness is highly variable (Steneck and Bulger, 2007; Phillips et al., 2018). As alluded to earlier, RECR training is mandatory for individuals who conduct research as part of a federallyfunded program (e.g., NSF-REU, NIH-R25). Outside these federally-funded initiatives, undergraduates conducting research under the apprenticeship of a faculty mentor might also have access to RECR education, but institutional policies differ. Historically, the RECR education of emergent scientists has occurred via unstructured and informal means that primarily include direct mentoring and enculturation of RECR practices during the research process (Steneck and Bulger, 2007). This approach places the full responsibility for RECR education of novice researchers on the research advisor and/or more experienced peers. Even then, the number of undergraduates who have access to traditional research apprenticeships is small, and a minority of undergraduates receive RECR instruction in such contexts. One recent study noted that, in some cases, RECR education of undergraduate researchers is limited to providing students with basic information via printed handouts rather than employing more purposeful activities (Phillips et al., 2018). Overall, such lack of attention to RECR education at the undergraduate level is worrisome in light of the recent effort at many institutions to incorporate research opportunities into the curriculum via course-based undergraduate research experiences (CUREs).

In addition to providing benefits comparable to mentored research experiences (Shapiro et al., 2015; Frantz et al., 2017), CUREs offer a potential solution to issues of access to and inclusion in undergraduate research opportunities (Bangera and Brownell, 2014; Estrada et al., 2016). Their format as a course that is integrated into the curriculum allows CUREs to engage larger numbers of students in research than the classic apprenticeship model. They also provide opportunities for students who might not have the ability to join a research laboratory as an extracurricular activity (Bangera and Brownell, 2014).

Studies on the impact of CUREs have shown that these courses facilitate undergraduates' science identity development, acquisition of research skills, and persistence in the sciences (Jordan et al., 2014; Shaffer et al., 2014; Ward et al., 2014; Brownell et al., 2015; Olimpo et al., 2016; Rodenbusch et al., 2016; Corwin et al., 2018; Esparza et al., 2020). Due to these benefits, many institutions have started offering CUREs in place of traditional biology laboratories. CUREs are being implemented via different modalities, including national models (e.g., SEA-PHAGES, the Genomics Education Partnership, the Small World Initiative, Tiny Earth; Shaffer et al., 2010; Jordan et al., 2014; Small World Initiative, 2020; Tiny Earth, 2020), institution-wide first-year initiatives (Rodenbusch et al., 2016; Collins et al., 2017), and course-specific CUREs (Wei and Woodin, 2011; Brownell et al., 2015; Sarmah et al., 2016; Fisher et al., 2018). Considering all modalities together, CUREs are being deployed at a myriad of institutions and provide undergraduate research opportunities to thousands of students every year. This has resulted in CUREs becoming a significant means of exposing undergraduate students to research in the biological sciences, among other disciplines.

Given the national diffusion of CUREs across the college biology landscape, we sought to understand how RECR education is integrated within CURE environments. A search of the literature revealed only a handful of reports documenting efforts to integrate RECR into undergraduate research experiences (Olimpo et al., 2017). The majority of these efforts focused on RECR education of undergraduates participating in classic mentored research experiences (e.g., summer undergraduate research experiences). For instance, the Council on Undergraduate Research recently published a "how-to" guide for RECR education of undergraduate researchers (Turrens and Springer, 2019). While this guide provides a list of RECR topics and example case scenarios, it does not specifically address the implementation of RECR education in CUREs. Only four papers addressed RECR integration within CUREs or inquiry-driven courses (Senchina, 2011; Hendrickson, 2015; Swanson et al., 2016; Wahila et al., 2017). These papers included: 1) suggestions to incorporate RECR topics throughout the curriculum in inquiry-driven biochemistry and molecular biology labs (Hendrickson, 2015); 2) using video-based case scenarios to educate undergraduate students in RECR topics related to human subjects research in exercise physiology laboratory courses (Senchina, 2011); 3) one session involving discussion of RECR within a freshman biology CURE (Swanson et al., 2016); and 4) incorporation of RECR education into the first semester of a three-semester physics and chemistry CURE series (Wahila et al., 2017). Although these publications include a variety of approaches to RECR integration, it is evident that there is a lack of reports and resources to facilitate RECR instruction in CUREs.

In response to this need, the Ethics Network for Coursebased Opportunities in Undergraduate Research (ENCOUR) was established in 2017 (Diaz-Martinez et al., 2019). This network aims to identify and develop ways for instructors to integrate RECR education into CUREs. With the intent of attaining this goal, ENCOUR held its first meeting in January of 2018. 
From conversations held at the initial meeting, we identified the need to conduct a national study to further understand the current state of RECR integration within biology CUREs. The specific questions guiding this exploratory study were:

1. To what extent, if at all, is RECR instruction included in CUREs?

2. What are the approaches used for RECR instruction in CUREs?

3. What RECR issues are most commonly encountered by CURE facilitators?

4. What RECR topics are most commonly addressed by CURE facilitators?

5. How is the effectiveness of RECR education in CUREs assessed?

6. What are the needs of the CURE community with respect to achieving effective integration of RECR education within CUREs?

Our findings indicate minimal presence of deliberate RECR instruction within CUREs and highlight both interest in and a need for resources to facilitate RECR integration within such spaces.

\section{METHODS}

To address the aforementioned questions, we adopted a sequential, mixed methods approach. Specifically, survey data were first obtained from participants $(N=66)$ to identify patterns in RECR education on a national scale. Semistructured interviews were then conducted with a subset of survey participants ( $n=13$ ) to provide additional detail regarding specific RECR instructional approaches used, potential benefits and barriers to effective RECR education, and self-identified needs that would allow for more efficient integration of RECR instruction within CUREs. The sole criterion for inclusion in the study was that respondents needed to be involved in the development, implementation, and/or evaluation of a biological sciences CURE at their institution. This research was approved by the University of Texas at El Paso's Institutional Review Board under protocol \#1123119.

\section{Survey Development and Deployment}

Survey questions were collaboratively developed by J.T.O., D.E., M.R., and C.E.D. during the initial ENCOUR meeting. The questions were then refined by J.T.O. and C.E.D. to improve clarity, resulting in the generation of a preliminary draft of the survey. This survey was created on the Qualtrics platform and fieldtested by L.A.D.-M. and J.M.B., who provided feedback to improve survey clarity and to further confirm that the questionnaire covered all pertinent topics related to RECR education in CUREs based on the focus of the research and prior studies (e.g., Resnik and Dinse, 2012).

To examine the face validity of the survey, J.T.O. distributed the questionnaire (via email) to all remaining ENCOUR members $(N=12)$, who had the opportunity to provide written and/ or oral feedback on the suitability and phrasing of each survey item based on their understanding of the item statement (Drost, 2011). These individuals were not involved in the development of the survey and so offered an unbiased perspective that allowed for additional refinement of the questionnaire. Furthermore, these individuals, while all familiar with CURE develop- ment, implementation, and/or evaluation practices, possessed diverse backgrounds in RECR subject matter and pedagogical content knowledge. These attributes mirrored those of the anticipated respondent population, which we found to be imperative to our survey development efforts. Likewise, the collective procedures used to gather evidence for the face validity of our survey reflected those steps described in previous studies employing survey measures designed to examine instructor praxis and professional development (Allen and Yen, 2001; Schussler et al., 2015; Großschedl et al., 2018).

Once finalized, the survey was broadly distributed via biology education Listservs, dissemination efforts at biology education conferences, and direct outreach by ENCOUR members to CURE stakeholders. Survey responses were collected from April 24, 2018, to August 8, 2018. A total of 113 surveys were initiated during the data acquisition period. Forty-four were incomplete with less than $20 \%$ of the questions answered and, therefore, were not included in our analysis. An additional three surveys were excluded because the topic of the CURE was not in the biological sciences (broadly defined) or because they pertained to capstone courses that were based on independent research projects rather than course-based research experiences. The remaining 66 surveys pertained to CUREs in the biological sciences (broadly defined) and were retained for analysis.

\section{Survey Description}

The survey began with a brief definition of CUREs (Auchincloss et al., 2014) to ensure that both the respondents and the research team had a clear and aligned understanding of what was considered a CURE for the purposes of this study (see Appendix 1 in the Supplemental Material for the complete survey). The survey itself consisted of 20 items covering four areas, as follows:

1. Demographic information: Questions in this category asked for information regarding the demographics of the respondents (e.g., race/ethnicity, gender identity) as well as information about the institution at which they work.

2. General course information: These questions were designed to capture information about the respondents' experiences with CUREs. Each respondent was asked to provide a short description of the CURE that they facilitate and to identify the person(s) who primarily deliver(s) the CURE instruction (e.g., themselves, faculty, teaching assistants [TAs]). Respondents were also asked to provide information regarding their own role(s) in facilitating the CURE, including and beyond that of instructor (if applicable; e.g., instructor, developer, coordinator), number of semesters teaching/facilitating the CURE, the academic level at which the CURE is offered, and the average class size of the CURE.

3. Information regarding RECR integration: In this series of questions, respondents were asked whether they have had to resolve RECR issues in their CUREs and, if so, which kind(s) of RECR issues they most frequently encountered. Respondents were also given a list of common RECR topics (adapted from DuBois and Dueker, 2009) and asked whether they provide RECR education for each of those topics within the context of their CUREs. Finally, respondents were asked how they integrate RECR education into their CUREs (i.e., what 
pedagogical approaches they use) and how the effectiveness of this education is assessed.

4. RECR education of students/instructors and RECR needs: Respondents were asked to provide information about the level of RECR education that is expected of students who enter their CUREs and about the type(s) of RECR education that they (the instructors) have received beyond institutionally-mandated RECR training. Respondents were likewise asked to indicate their level of interest in participating in a series of activities related to RECR integration within CUREs (e.g., establishing a network of colleagues for idea sharing, generating data and publications regarding CURE RECR topics).

At the end of the survey, the respondents were asked to provide their contact information if they were interested in participating in an optional follow-up interview.

\section{Semistructured Interviews}

Phone interviews were conducted with all 13 survey participants who expressed interest in voluntarily participating in a follow-up interview. Interviewees were asked to elaborate upon the potential benefits of and obstacles to incorporating RECR education into CUREs, the current level of integration of RECR instruction within their CUREs, and the specific needs of the CURE community that could be addressed to promote effective RECR integration within such learning environments (see Appendix 2 in the Supplemental Material for a list of all interview prompts).

\section{Data Analysis}

Survey responses were analyzed in Microsoft Excel to obtain descriptive statistics. Semistructured interviews were transcribed and analyzed using a descriptive-interpretative approach (Tesch, 2013). This involved the application of inductive methods to systematically and comprehensively ascertain patterns across participant responses (Elliott and Timulak, 2020). More specifically, each interview was coded in its entirety by two researchers with expertise in biology education (J.T.O. and A.A.H.), who independently identified emergent themes in the data set through iterative cycles of open and axial coding (Corbin and Strauss, 2015). Five transcripts were selected at random for the first cycle and reviewed by both coders, leading to the development of an initial codebook. The raters then met in person to discuss their codes, remove redundant codes, and propose new codes. All transcripts were then coded by both J.T.O. and A.A.H. using the updated codebook. The raters met again in person following this process to confirm that no new codes were needed, establish final interrater reliability (IRR), and achieve consensus coding. Strong IRR, as measured via Cohen's kappa, was observed $(\kappa=0.854 ; p<0.001 ; 95 \%$ confidence interval $[0.794,0.914])$.

\section{RESULTS}

\section{Respondent Demographic, Institutional, and} CURE Information

Participants $(N=66)$ predominantly self-identified as white (79\%) and female (70\%; Table 1). They furthermore represented a variety of self-identified institution types, including public universities (59\%), private universities (23\%), 4-year colleges (52\%), 2-year colleges (17\%), liberal arts colleges
TABLE 1. Participant demographics and CURE characteristics

\begin{tabular}{|c|c|}
\hline Role of respondents in the CURE & No. of respondents (\%) \\
\hline Instructor & $24(36)$ \\
\hline Developer & $2(3)$ \\
\hline Director/coordinator & $4(6)$ \\
\hline Developer and instructor & $14(22)$ \\
\hline Director/coordinator and instructor & $16(24)$ \\
\hline Director/coordinator and developer & $2(3)$ \\
\hline All roles & $4(6)$ \\
\hline CURE topic(s) addressed ${ }^{a}$ & No. of respondents (\%) \\
\hline Microbiology & $23(35)$ \\
\hline National CURE models & $14(22)$ \\
\hline Plant biology & $14(22)$ \\
\hline Cell/molecular biology and/or genetics & 12 (19) \\
\hline Student-driven topic & $7(11)$ \\
\hline Immunology, histology & $2(3)$ \\
\hline Biotechnology & $3(4)$ \\
\hline Other & $11(17)$ \\
\hline Academic level of the CURE & No. of respondents (\%) \\
\hline Freshman & $12(19)$ \\
\hline Sophomore & $7(11)$ \\
\hline Freshman and sophomore & $13(20)$ \\
\hline Junior & $3(4)$ \\
\hline Senior & $10(15)$ \\
\hline Junior and senior & $10(15)$ \\
\hline All levels & $3(4)$ \\
\hline Other combinations & $8(12)$ \\
\hline $\begin{array}{l}\text { Average number of students enrolled in } \\
\text { each CURE section }\end{array}$ & No. of respondents (\%) \\
\hline$<15$ & $13(20)$ \\
\hline $15-20$ & $23(35)$ \\
\hline $21-25$ & $20(30)$ \\
\hline $26-30$ & $3(4)$ \\
\hline$>30$ & $7(11)$ \\
\hline Race and/or ethnicity of respondents & No. of respondents (\%) \\
\hline Caucasian (White) & $52(79)$ \\
\hline Latino/Hispanic & $8(12)$ \\
\hline Asian & $2(3)$ \\
\hline Multiracial/multiethnic or other & $3(4)$ \\
\hline Prefer not to indicate & $1(2)$ \\
\hline Gender of respondents & No. of respondents (\%) \\
\hline Female & $46(70)$ \\
\hline Male & $20(30)$ \\
\hline
\end{tabular}

${ }^{a}$ Note that the sum of all percentage values in this category exceeds $100 \%$, as respondents could select more than one topic area.

(27\%), research universities (42\%), comprehensive universities (17\%), Hispanic-serving institutions (HSI; 14\%), and minority-serving institutions (non-HSI; 11\%). Note that respondents were asked to select all characteristics that applied to their institutions. Thus, the sum of the percentages is greater than $100 \%$. Moreover, participants served in various roles within their respective CUREs (e.g., instructor, developer). They also facilitated a diverse array of course-specific and national CURE models (e.g., biotechnology CURE, plant biology CURE, SEA-PHAGES) across both lower- and upper-division courses with varied levels of student enrollment (Table 1). 


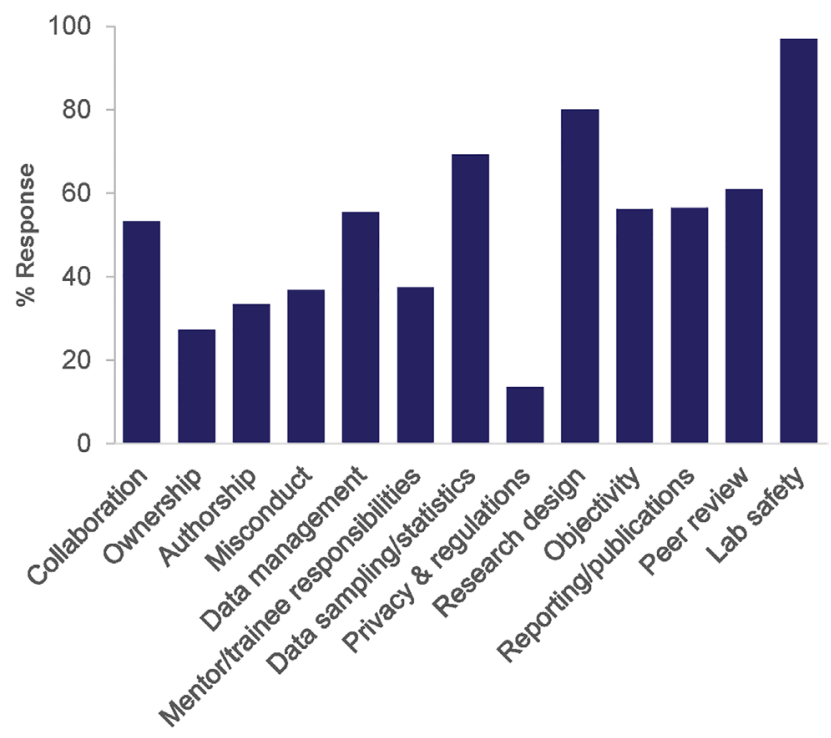

FIGURE 1. RECR issues (collaboration, ownership, authorship, and misconduct) that respondents have had to resolve and RECR topics (data management through lab safety) that respondents provide specific training on within their CUREs. Please note that, in calculating the percentages represented in this figure, individuals who indicated "N/A" for the stated RECR area were excluded from the total respondent count for that area.

\section{Current Level of RECR Integration within CUREs}

To examine the current RECR practices employed by CURE facilitators nationwide, we asked respondents to indicate the level of RECR education that they expect students to possess when entering their CUREs, as this may impact planned and enacted RECR curricula for their courses (Fuller, 2002; Lynch and Smith, 2011). The majority (86\%) of respondents indicated that they do not expect students entering their CUREs to have any prior RECR education. The remaining respondents expected students to have moderate RECR education. Because CUREs are often the first research experience for undergraduate students, as suggested by the $43 \%$ of survey respondents who indicated that their CUREs were open to freshmen, it is not surprising that most instructors expect their students to have no prior RECR education.

Next, we asked the respondents to indicate whether they have had to resolve certain RECR issues within their CUREs (see Appendix 1 in the Supplemental Material, Q14). Of those respondents for whom the following RECR areas were relevant to their CUREs, 53\% reported having to resolve issues related to collaboration, $27 \%$ reported having to resolve issues with respect to ownership, 33\% reported having to resolve issues regarding authorship, and $37 \%$ reported having to resolve issues concerning research misconduct (Figure 1). The saliency of RECR issues related to collaboration, in particular, is most likely due to the highly-interactional nature of CUREs (Auchincloss et al., 2014; Esparza et al., 2020).

We then provided respondents with a list of common RECR topics (adapted from DuBois and Dueker, 2009; see Appendix 1 in the Supplemental Material, Q15) and asked them to indicate which of those topics they provide specific training on in their CUREs. Interestingly, all respondents stated that they address at least one of nine RECR topics in their courses (Figure 1). For those individuals for whom the following RECR topics were relevant to their CUREs, the areas that were most often addressed were: lab safety (97\%), research design (80\%), and data sampling/statistics (69\%). We were particularly surprised to see that only $37 \%$ of applicable respondents addressed mentor/trainee responsibilities, as CUREs are often argued to represent an intensive mentoring environment (Dolan, 2016; Hensel, 2018).

Because students may be new to the research environment, we posit that CURE facilitators might choose to emphasize ethical experimental design and safe laboratory practices rather than other aspects of RECR. In addition, some of the RECR topics might not apply to all CUREs. For example, issues of privacy and protection of human subjects would not be germane to CUREs that do not include human participants. Therefore, effective integration of RECR education within CUREs must consider the relevance of the RECR topics to the CURE and emphasize those topics accordingly.

Overall, these results suggest that RECR integration within biology CUREs is already occurring to some extent. Yet, given the percentage of respondents reporting RECR issues within their CUREs and the importance of RECR education to the scientific enterprise, we argue that the level of RECR integration needs to be increased.

\section{Current and Future Approaches to RECR Education in CUREs}

To gain further insight into how RECR education is currently integrated within biology CUREs, we asked survey respondents to provide information regarding the RECR instructional approaches that they use in their CUREs. Results indicate that two primary methods are employed (Figure 2A): 1) corrective instruction when an issue arises, which was used at least occasionally by $95 \%$ of respondents, with $34 \%$ of participants using this method exclusively or frequently; and 2) context-based education, which entails addressing RECR topics when relevant to the practice of science within the CURE. This latter method was used at least occasionally by $70 \%$ of respondents, with $50 \%$ of respondents using this method exclusively or frequently. Note that these percentages and those shown in Figure 2A exclude individuals who indicated "N/A" for the stated method from the total respondent count for that method. We then asked at which point(s) during their CUREs respondents introduce RECR topics. More than half of the respondents (58\%) introduce RECR topics only when relevant, $18 \%$ of respondents introduce RECR at the beginning of the course, and $24 \%$ of respondents do so at multiple times (Figure 2B). Finally, we asked the respondents about the RECR instructional approach(es) that they use in their CUREs. The most commonly-cited approach was the practical application of RECR principles. Specifically, this entails providing opportunities to learn RECR concepts by applying those principles while conducting research (e.g., learning about record keeping by maintaining a research notebook that is periodically reviewed by the instructor). This was followed by case studies, lecture, and written assignments (Figure 2C). As was the case earlier, note that the percentages specified in Figure $2 \mathrm{C}$ exclude individuals who indicated "N/A" for the stated approach from the total respondent count for that approach. Collectively, these results suggest that, at present, the integration of RECR education within CUREs is mostly done on an 'as needed' basis 
A.

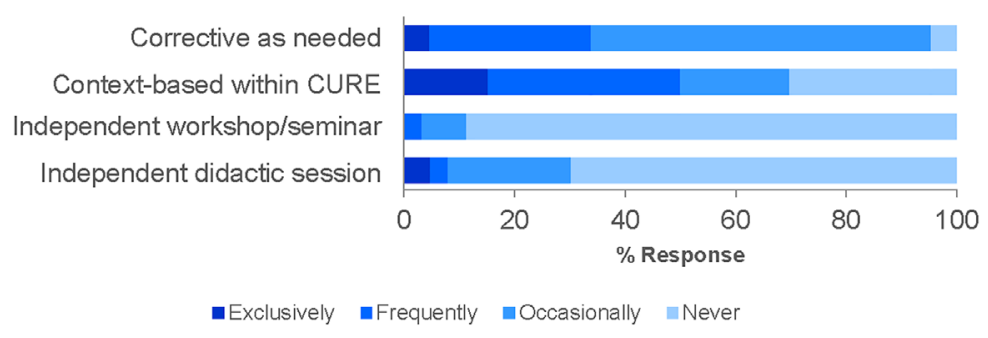

C.

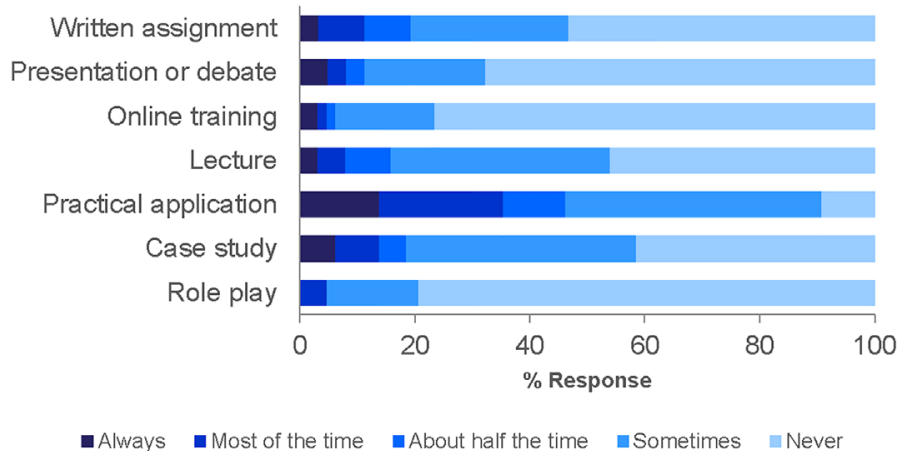

B.

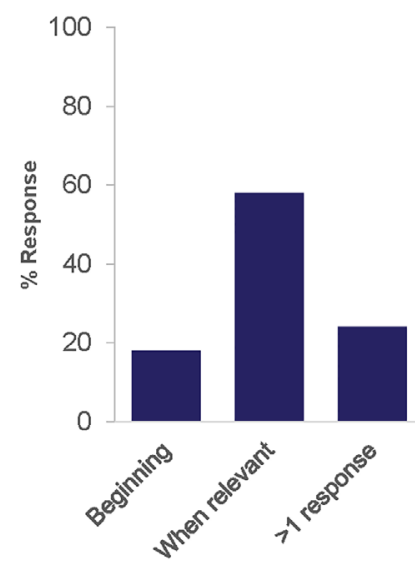

FIGURE 2. RECR education timing and instructional approaches used by survey participants. (A) Methods used by CURE facilitators to integrate RECR topics within their CUREs. (B) Timing of RECR instruction. (C) Instructional approaches used for RECR education.

whenever issues arise or when such education is relevant to the practical needs of the course.

To acquire a better understanding of the instructional strategies used by participants, we expanded on this topic during the semistructured interviews by asking interviewees to briefly describe examples of how they incorporate RECR education into their CUREs. The theme that emerged most frequently was discussions of RECR concepts and practices (77\% of responses), which seemed to occur primarily via in-class group dialogue. Congruent with the data presented in Figure 2C, other examples of how interviewees integrate RECR within their CUREs included using case studies, discussion of primary/secondary literature, or via student-led presentations. Sample responses for these and other themes identified are provided in Table 2. Additionally, some of the interviewees described strategies that they would like to implement in the future. We elected to retain these responses as part of our analysis, as we contend that they reflected participants' mindsets regarding what they perceived to be useful RECR educational approaches and/or potential planned curricula for future use in their CUREs.

\section{Perspectives from CURE Facilitators Regarding the Benefits of RECR Education}

As shown in Figure 1, respondents self-reported addressing a diversity of RECR topics in their CUREs. We next sought to understand what these individuals perceived as the benefits of incorporating RECR education into such learning environments. Analysis of interview data revealed two primary themes: 1) RECR education would contribute to the trainees' understanding of the process of science ( $85 \%$ of responses), and 2) RECR education would promote trainees' professional advancement ( $85 \%$ of responses). Interestingly, several responses men- tioned that RECR education would strengthen trust in scientific information (38\%). Selected interviewee responses that exemplify these themes are included in Table 3. Collectively, these responses reinforce that CURE facilitators are aware of and value the importance of RECR to the research process and to the development of emerging scientists.

\section{Assessment of RECR Education}

We then asked the participants to identify the approaches that they use to assess RECR education in their CUREs. A majority of survey respondents (76\%) reported that they do not use any form of assessment. For the minority of respondents who assess RECR-related outcomes $(n=16)$, the preferred techniques were: 1) evaluating assignments that include RECR components (50\%) and 2) formative assessment of students' successful implementation of RECR standards in their research (44\%). Assignments that assessed RECR learning included reflections on RECR topics, presenting and debating controversial RECR case scenarios, and writing and/or evaluating mock Institutional Animal Care and Use Committee (IACUC) proposals. Assessment of students' application of RECR concepts focused mainly on checking their research notebooks (e.g., record accuracy, proper data management) as well as evaluating the appropriateness of their experimental designs. Of note, 38\% of survey respondents who assess RECR-related outcomes use multiple types of assessment.

Taken together, these results indicate that RECR education is recognized as an important component of CURE curricula. Importantly, instructors are already incorporating RECR topics into their CUREs to some degree. However, the focus seems to be on the practical application of RECR principles, and the majority of CURE facilitators in our sample self-reported that 
TABLE 2. Interviewee responses to the prompt: "Please briefly describe an example of how you integrate ethics/RCR into your CURE and for what purpose(s)."

Theme: Discussion of RECR concepts and practices

Number of responses $(\%)^{\mathrm{a}}: 10(77 \%)$

Sample interviewee responses:

- "We also talk about just the deeper ethical issues of working in groups and teams. Research responsibilities-so that people are investing time and energy into things and what kinds of responsibilities we have when we're working in groups. But also, with science, we're generally not just working in our team of researchers, but we rely heavily on staff, on student volunteers, and things like that. And that comes up with my students a lot. How to interact with a greenhouse manager in a way that is respectful."

- "So, they are learning about a history incident, and they end up debating the pros and cons or the rights and wrongs of that. Through that process, we bring in discussion points about, what was optimal? What was fair? What was not fair? How should it have been done?"

Theme: Primary/secondary literature

Number of responses (\%): $2(15 \%)$

Sample interviewee responses:

- "We do [a] history of science. They read books and biographies or autobiographies of scientific discoveries or scientific lives. For example, Double Helix by Watson, What Mad Pursuit by Crick, and things like that."

- "We wanted [the students] to be able to read scientific literature critically."

Theme: Presentations Number of responses (\%): $1(8 \%)$

Sample interviewee response:

- "We had students divide into groups, and I think we do weekly presentations on different ethics/RCR topics ... and students were given resources, and articles, and books to read, and then were instructed to come up with an interactive, light, not super curious, but informative and fun presentation."

Theme: TA professional development Number of responses (\%): $1(8 \%)$

Sample interviewee response:

- "So, one of my potential ideas is - we have a workshop for our new TAs ... there should be a unit on ethics and RCR without question. [One] that's more active learning; not the CITI training."

Theme: Case studies

Number of responses (\%): $2(15 \%)$

Sample interviewee responses:

- "I'm imagining, perhaps, having students work through some scenarios, where maybe they're given some real-life scenarios ... where they have to actually explore that ... just some way to immerse them in some sort of story or context of ethics gone awry to help them see that and then reflect back on how that applies to them."

- "One of the big RCR cases we do is one my wife and I wrote on engineering yeast to make a certain Omega-3 fatty acid ... [it] was a really great introduction to some of the ethical implications of metabolic engineering."

Theme: No response provided

Number of responses (\%): $1(8 \%)$

${ }^{a} n=13$; participant responses were coded into multiple categories, as appropriate.

they do not assess RECR learning despite finding RECR valuable (see Table 3 for examples of potential benefits identified by interviewees). These results highlight a need for more intentionally-designed approaches to integrate and assess RECR topics in biology CUREs.

\section{Facilitator Training, Perceived Obstacles to RECR Education in CUREs, and Community Needs}

Hesitancy toward integrating RECR topics within CUREs may be fostered by a lack of experience and/or effective RECR training of the facilitators themselves. To explore this assumption, we asked respondents whether they have ever participated in RECR professional development opportunities beyond the trainings mandated by their institutions. If so, we asked them to identify the type(s) of training received. This query revealed that $55 \%$ of participants had received additional training, which included optional institutional training (e.g., workshops), online training, or a combination of various training modalities (Figure 3A). Conversely, $45 \%$ of CURE facilitators had only received mandatory RECR training. When prompted to discuss potential obstacles for incorporating RECR education into their CUREs, interviewees cited this lack of additional RECR training (Table 4).

Overall, the most common obstacles identified by the interviewees were insufficient time within the CURE to address RECR topics (85\% of responses), course alignment concerns
(85\% of responses), and lack of materials and resources (46\% of responses). CURE instructors perceive that the amount of time and resources dedicated to facilitating a CURE is already a significant barrier for implementation (Shortlidge et al., 2016). Thus, it is not surprising to find these same concerns expressed with respect to RECR education in CUREs.

Finally, we wished to identify the types of efforts that individuals might engage in to enhance the incorporation of RECR instruction into their CUREs. A majority of the survey respondents were interested in establishing a core set of principles for RECR integration within CUREs, learning how to assess students' RECR comprehension, and discovering effective instructional interventions for RECR education within the context of CUREs (Figure 3B). Further elaboration during the interviews revealed that the items participants were most interested in were a toolkit for instructors to help facilitate the integration of RECR education within a CURE ( $92 \%$ of responses) as well as the development of specific guidelines for RECR integration within CURE environments (62\% of responses; Table 5).

\section{DISCUSSION}

The results of this study provide an overview of the current level of integration of RECR education within biology CUREs nationwide. Survey and semistructured interview data revealed that CURE facilitators are aware of the importance and benefits of 
TABLE 3. Interviewee responses to the question: "What do you believe are the potential benefits related to introducing ethics/RCR education within CUREs, and why?"

Theme: Understanding the process of science

Number of responses $(\%)^{\mathrm{a}}: 11(85 \%)$

Sample interviewee responses:

- "Science isn't done in a vacuum, but there are implications ... [by] implementing [ethics] early then in your undergraduate education, it kind of just makes it more normal like that you're going to be doing this. So, it normalizes it is sort of part of the scientific process."

- "It helps the students to have a more complete understanding of the process of science ... I think [ethics] is just as much [a part] of the process of science as teaching them how to use a piece of equipment or a technique or statistics."

Theme: Professional advancement

Number of responses (\%): $11(85 \%)$

Sample interviewee responses:

- "I would also think that just from a very practical standpoint, you know, when students are applying for programs after they leave here, whether it be a grad program, or I could even think in medical school, you know, those that are applying for professional schools ... having this type of skill set could be a benefit in being able to write about the different types of training that they've had."

- "If we introduce them to this early and help put these ethics into a larger context, if they go on to become scientists, ideally, they would be more ethical and be aware of how to navigate ethics in their professional careers."

Theme: Trust in scientific information $\quad$ Number of responses (\%): 5 (38\%)

Sample interviewee responses:

- "For students that aren't necessarily going to be scientists, I think it's important that they understand the science literacy aspect of it. So, how do scientists work, and how do we trust, when something is published, that it's actually correct and not just a bunch of made-up lies. So, I think including the ethics for those students-ethics and RCR-is important in that aspect."

- "It certainly helps with being a member of society and kind of understanding what it is that scientists are doing, since they're making so many decisions that are impacting our lives. And those same ethical decisions are actually impacting citizens' lives."

Theme: Increased interest in research/ethics

Number of responses (\%): $1(8 \%)$

Sample interviewee response:

- "Teaching them more about the ethical side of science could, like, instill more trust in research or interest in research."

Theme: Decrease in unethical behavior

Number of responses (\%): $4(31 \%)$

Sample interviewee responses:

- "Kind of just showing them an appreciation for being responsible when it comes to data acquisition and analysis so that they're not just trying to fudge numbers to get a good grade."

- "So, immediate benefits are, hopefully, we have fewer issues in the classroom or in the lab with the students maybe doing things that we, as scientists, would consider unethical."

${ }^{a} n=13$; participant responses were coded into multiple categories, as appropriate.

incorporating RECR education into CUREs. Notably, several interviewees commented on the need to integrate RECR instruction as a means to provide students with knowledge of the RECR standards in the discipline as well as to allow them to begin to internalize these standards as a central part of the research process.

Despite the low number of published reports on RECR integration within CUREs (Olimpo et al., 2017; Diaz-Martinez et al., 2019), our survey revealed that CURE facilitators are already

A.

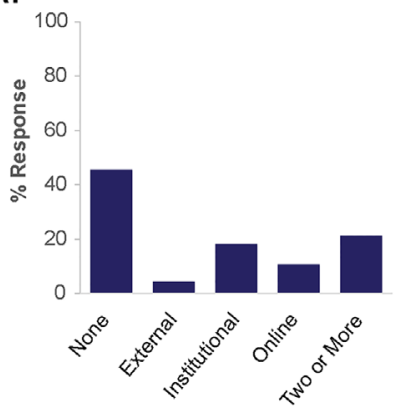

FIGURE 3. CURE facilitators' RECR training and needs. (A) RECR training received by CURE facilitators beyond institutionally mandated training. (B) Respondents' level of interest in participating in future activities related to the indicated topics. addressing at least one RECR topic in their courses (Figure 1). However, these efforts seem to be focused on introducing RECR education only when needed and often in response to ethical issues as they arise in the CUREs (Figure 2A). Participants reported addressing laboratory safety, research design, and data sampling/statistics most frequently in their courses. This likely reflects the fact that CUREs are often the first exposure students have to the research process (Rodenbusch et al., 2016). Thus, the RECR concepts that instructors deem most pertinent are those related to basic research procedures. Respondents likewise commonly reported addressing data management and objectivity. These foci are particularly important for CUREs that plan to include the students' results within publications, which requires that students obtain trustworthy data. Recent studies suggest that students in traditional laboratories (i.e., those that use confirmatory exercises) tend to engage in questionable research practices when their results deviate from the expected results (Stein et al., 2018; Smith et al., 2020). Because most students have only experienced confirmatory laboratory exercises before entering a CURE, emphasis on RECR practices surrounding the aforementioned 
TABLE 4. Interviewee responses to the question: "What do you believe are the potential obstacles related to introducing ethics/RCR education within CUREs, and why?"

Theme: Time

Number of responses $(\%)^{\mathrm{a}}: 11(85 \%)$

Sample interviewee responses:

- "I think the biggest obstacle is just time ... it's just choosing what is the most valuable [thing] to do with their (students') very, very limited time."

- “The biggest [obstacle] is just time ... 'How do I use these minutes?' I think that's the biggest one."

Theme: Lack of materials and resources

Number of responses (\%): $6(46 \%)$

Sample interviewee responses:

- "The other thing, too, would be the instructor's side, just developing the materials for this ... I'd feel a little overwhelmed just being me as one person, having to be like, 'Okay, well what's important? What should I bring up?'... It would be nice if I could go on the Web somewhere and find a toolkit to be able to start with."

- "So, I think having some sort of toolkit or toolbox."

Theme: Lack of professional development

Number of responses (\%): $4(31 \%)$

Sample interviewee responses:

- "I don't have the ethics training myself."

- "I'm not trained in bioethics and that kind of thing."

Theme: Level of student preparedness

Number of responses (\%): 4 (31\%)

Sample interviewee responses:

- "The two CUREs I've done have both been freshman-level CUREs, and, so, you're getting very novice students as a whole. There are always the exceptions that know what's going on, but most of them are novice[s]."

- "Meaning, since they haven't done research already, they might not be able to relate to every aspect of RCR while in [a] CURE."

Theme: Student resistance/lack of compliance

Number of responses (\%): 2 (15\%)

Sample interviewee responses:

- "Students also often-you know, especially you can imagine with part-time instructors, where more of their job security is kind of based off student satisfaction in the course-a lot of science students complain when you have them do things that they don't view as kind of central, core science ideas ... So, spending real class time on just thinking about research ethics would probably turn off some students."

- "If you have three lab sections or something, it's hard to check data [for] 60 students and ensure that they're following RCR training ... I think it would be hard to ensure that the students are actually following these guidelines."

Theme: Faculty resistance

Number of responses (\%): $3(23 \%)$

Sample interviewee responses:

- "I just think about all of our independent faculty and how, sometimes, it's like herding cats to get us all to agree on something-is getting everyone to agree on whatever ethics are supposedly important for us to focus on ... Unfortunately, I think we all have people who come from a place of 'no,' who don't want to change for any number of reasons and are pretty adamant about that."

- "I feel like an obstacle is that professors don't actually think it's important in the class or don't understand how it fits in with the bigger [picture]."

Theme: Course alignment

Number of responses (\%): $11(85 \%)$

Sample interviewee responses:

- "It doesn't really align generally with most of the learning objectives for departments or for courses. And if it does, it's usually just one."

- "[How do you incorporate ethics] so that you can still maintain progress in that class (a CURE) and attain your lab-based goals as well as, in our case, the accompanying lecture goals and student learning outcomes [for] those classes."

${ }^{a} n=13$; participant responses were coded into multiple categories, as appropriate.

topics is key. However, it was interesting to see that some individuals are also incorporating other RECR topics in ways that are relevant to the broader theme of their CUREs-for example, addressing RECR concepts related to animal subjects by having the students write and review mock IACUC applications (see also, Table 2).

Our analyses furthermore revealed important gaps, barriers, and needs for effective RECR integration within CUREs. Most striking was the finding that roughly three-quarters of respondents self-reported that they do not currently assess any aspects of RECR in their CUREs. The reasons for this lack of assessment were not clear. We hypothesize that this might be because at least some of the respondents see RECR education as an "add-on" to the course (as suggested by interviewee responses provided in Table 4) or because of the difficulty associated with assessing RECR values or behaviors rather than content knowl- edge (Steele et al., 2016). It is also possible that participants' self-reported lack of RECR assessment was due to the limited availability of metrics to evaluate student-level RECR outcomes within CUREs (Diaz-Martinez et al., 2019). Indeed, a lack of resources was often cited as one of the barriers to incorporation of RECR education into CUREs, and slightly more than $60 \%$ of survey respondents expressed that they were at least moderately interested in learning more about RECR assessments (Figure 3B). Further discussion with the interviewees suggested the need for a toolkit containing resources (activities, assessments, and otherwise) and examples for RECR instruction that are relevant to the CURE environment. Clearly, there is a need for a concerted effort within the CURE community to jointly develop these resources.

In addition to the need for resources, lack of time was frequently cited as a significant barrier. CUREs require students 
TABLE 5. Interviewee responses to the question: "One of the goals of our network is to serve the needs of the community with respect to integration of ethics/RCR education within CUREs. What recommendations do you have in terms of initiatives or specific needs that our network should address to assist the community in achieving better integration of ethics/RCR within CUREs?"

\begin{tabular}{lc}
\hline Response & $\begin{array}{c}\text { Number of responses } \\
(\%)^{\mathrm{a}}\end{array}$ \\
\hline Resource toolkit & $12(92 \%)$ \\
RECR in CUREs guidelines & $8(62 \%)$ \\
Personal/professional development & $5(38 \%)$ \\
Central RECR "hub"b & $7(54 \%)$ \\
Emphasis on diversity, equity, and inclusion & $1(8 \%)$ \\
\hline
\end{tabular}

${ }^{a} n=13$; participant responses were coded into multiple categories, as appropriate. bNote that the "hub" should involve individuals from diverse disciplines with diverse levels of experience in their fields and in CURE development/instruction.

and instructors to spend considerable time conducting research and ensuring that everyone is learning the information and skills needed to advance their projects (Auchincloss et al., 2014). Thus, it is not surprising that $85 \%$ of interviewees indicated that finding the time to integrate RECR topics into their CURE was a challenge that they had encountered or anticipated encountering (Table 4). Based on these comments, we posit that the best way to integrate RECR education into CUREs might be through a series of short but highly-relevant activities deployed throughout the semester. This would allow instructors to address RECR topics in a time-efficient way and would allow for continuous discussion of topics on the days when they are most relevant to the activities being performed (Hendrickson, 2015). Importantly, integration of RECR education within CUREs must not be a one-off effort and must use effective pedagogies. Development of an ethical mindset takes time, and the effectiveness of RECR education has been shown to be highly dependent on the pedagogical approach used to facilitate such instruction (Antes et al., 2009; Steele et al., 2016; Watts, Mulhearn et al., 2017). Thus, while the "just-in-time teaching" strategies (Marrs and Novak, 2004) described by participants in this study are arguably valuable in providing new RECR knowledge and skills to students at the moments when they need them, we strongly advocate for the intentional inclusion of RECR student learning objectives, activities, and assessments from the outset of planning one's CURE (Olimpo et al., 2017; Diaz-Martinez et al., 2019).

Finally, some of the respondents expressed a need for additional opportunities to increase their awareness and knowledge of RECR, including how to develop their own RECR educational resources. These opportunities were perceived as being distinct from institutionally-mandated RECR trainings that focus on RECR standards (Mulhearn et al., 2017; Watts, Medeiros et al., 2017). For such professional development to be effective, a scaffolded, iterative approach focused on the multiple dimensions (e.g., assessment, core RECR tenets) of RECR education within CUREs should be adopted (Diaz-Martinez et al., 2019).

\section{LIMITATIONS AND CONCLUSIONS}

We acknowledge that there are several limitations inherent in our study. First, our sample size is small and underrepresents the total number of individuals involved in CURE instruction and/or RECR education in CUREs nationwide. While this is not uncommon of exploratory studies (see Schussler et al., 2015, as an example), we caution against overgeneralization of the results presented herein. Relatedly, self-response bias could influence these results, with those individuals especially interested in CURE and/or RECR educational practices being more likely to respond than others. To address these potential issues, we distributed multiple requests for participation through a variety of science education venues so as to recruit as robust and diverse a sample as possible. Regardless, we wish to reaffirm that this research is intended to provide an initial depiction of RECR education in biology CUREs in the United States. Future studies should be conducted to further explore the nuances of RECR instruction in such contexts, RECR education with respect to other science, technology, engineering, and mathematics (STEM) and non-STEM CUREs, and other related areas of investigation.

Our results indicate clear awareness of and enthusiasm for the importance of integrating RECR education into CUREs in the biological sciences. Currently, these efforts are mostly led by CURE facilitators who individually decide to incorporate one or more RECR topics into their courses rather than being a planned effort within the biology CURE community. Our results also reveal prominent obstacles limiting the incorporation of RECR instruction into CUREs, namely: lack of time, resources, and professional development opportunities. Given that CUREs often constitute the first research experience for many undergraduates and provide access to scientific research beyond that which is capable through traditional apprenticeships alone (Bangera and Brownell, 2014), we believe that research integrity is a key topic that should be addressed in all CUREs. Further, we advise that the best approach to achieve purposeful and effective RECR education in these courses is by the joint effort of all stakeholders. A concerted effort is thus needed within the CURE community to develop resources, unified language, and effective pedagogical models to achieve RECR integration within biology CUREs.

\section{ACKNOWLEDGMENTS}

Support for this work was provided by the NSF (NSF DBI1727867, NSF DBI-1919312). Any opinions, findings, and conclusions or recommendations expressed in this material are those of the authors and do not necessarily reflect the views of the NSF.

\section{REFERENCES}

ALLEA. (2017). The European code of conduct for research integrity (rev ed.). Retrieved August 20, 2020, from www.allea.org

Allen, M. J., \& Yen, W. M. (2001). Introduction to measurement theory. Waveland Press.

America COMPETES Act. (2007). Pub. L. No. 121 STAT. 572.

Antes, A. L., Murphy, S. T., Waples, E. P., Mumford, M. D., Brown, R. P., Connelly, S., \& Devenport, L. D. (2009). A meta-analysis of ethics instruction effectiveness in the sciences. Ethics \& Behavior, 19(5), 379-402. doi: 10.1080/10508420903035380

Auchincloss, L. C., Laursen, S. L., Branchaw, J. L., Eagan, K., Graham, M. Hanauer, D. I., ... \& Dolan, E. L. (2014). Assessment of course-based undergraduate research experiences: A meeting report. CBE-Life Sciences Education, 13(1), 29-40. doi: 10.1187/cbe.14-01-0004

Bangera, G., \& Brownell, S. E. (2014). Course-based undergraduate research experiences can make scientific research more inclusive. CBE-Life Sciences Education, 13(4), 602-606. doi: 10.1187/cbe.14-06-0099 
Braunschweiger, P., \& Goodman, K. W. (2007). The CITI program: An international online resource for education in human subjects protection and the responsible conduct of research. Academic Medicine, 8(9), 861-864.

Brownell, S. E., Ekmat-Scafe, D. S., Singla, V., Chandler Seawell, P., Conklin Imam, J. F., Eddy, S. L., ... \& Cyert, M. S. (2015). A high-enrollment coursebased undergraduate research experience improves student conceptions of scientific thinking and ability to interpret data. Cell Biology Education, 14(2), ar21-ar21. doi: 10.1187/cbe.14-05-0092

Collins, T. W., Aley, S. B., Boland, T., Corral, G., Cox, M. B., Echegoyen, L. E., .. \& Nazeran, H. (2017). BUILDing SCHOLARS: Enhancing diversity among U.S. biomedical researchers in the Southwest. BMC Proceedings, 11(S12), 12. doi: 10.1186/s12919-017-0095-4

Corbin, J., \& Strauss, A. (2015). Basics of qualitative research (4th ed). Thousand Oaks, CA: SAGE Publications, Inc.

Corwin, L. A., Runyon, C. R., Ghanem, E., Sandy, M., Clark, G., Palmer, G. C., ... \& Dolan, E. L. (2018). Effects of discovery, iteration, and collaboration in laboratory courses on undergraduates' research career intentions fully mediated by student ownership. CBE-Life Sciences Education, 17(2), ar20. doi: 10.1187/cbe.17-07-0141

Diaz-Martinez, L. A., Fisher, G. R., Esparza, D., Bhatt, J. M., D’Arcy, C. E., Apodaca, J., ... \& Olimpo, J. T. (2019). Recommendations for effective integration of ethics and responsible conduct of research (E/RCR) education into course-based undergraduate research experiences: A meeting report. CBE-Life Sciences Education, 18(2), mr2. doi: 10.1187/cbe.18-10-0203

Dolan, E. L. (2016). Course-based undergraduate research experiences: Current knowledge and future directions. Retrieved June 2, 2021. from https://sites.nationalacademies.org/cs/groups/dbassesite/documents/ webpage/dbasse_177288.pdf

Drost, E. (2011). Validity and reliability in social science research. Education Research and Perspectives, 38(1), 105-123.

Dubois, J., \& Dueker, J. (2009). Teaching and assessing the responsible conduct of research: A Delphi consensus panel report. Journal of Research Administration, 40(1), 49-70.

Elliott, R., \& Timulak, L. (2020). Essentials of descriptive-interpretive qualitative research: A generic approach. Washington, DC: American Psychological Association.

Esparza, D., Wagler, A., \& Olimpo, J. (2020). Characterization of instructor and student behaviors in CURE and non-CURE learning environments: Impacts on student motivation, science identity development, and perceptions of the laboratory experience. CBE-Life Sciences Education, 19(1), ar10. doi: 10.1187/cbe.19-04-0082

Estrada, M., Burnett, M., Campbell, A. G., Campbell, P. B., Denetclaw, W. F. Gutiérrez, C. G., ... \& Zavala, M. (2016). Improving underrepresented minority student persistence in STEM. CBE-Life Sciences Education, 15(3), es5. doi: 10.1187/cbe.16-01-0038

Fisher, G. R., Olimpo, J. T., McCabe, T. M., \& Pevey, R. S. (2018). The Tigriopus CURE-A course-based undergraduate research experience with concomitant supplemental instruction. Journal of Microbiology \& Biology Education, 19(1). doi: 10.1128/jmbe.v19i1.1503

Frantz, K. J., Demetrikopoulos, M. K., Britner, S. L., Carruth, L. L., Williams, B. A., Pecore, J. L., ... \& Goode, C. T. (2017). A comparison of internal dispositions and career trajectories after collaborative versus apprenticed research experiences for undergraduates. CBE-Life Sciences Education 16(1), ar1. doi: 10.1187/cbe.16-06-0206

Fuller, K. R. (2002). An inquiry into the application of the curriculum chart in science education (Master's theses 564). Allendale, MI: Grand Valley State University. Retrieved August 20, 2020, from http://scholarworks.gvsu edu/theses/564

Großschedl, J., Welter, V., \& Harms, U. (2018). A new instrument for measuring pre-service biology teachers' pedagogical content knowledge: The PCK-IBI. Journal of Research in Science Teaching, 56(4), 402-439.

Health and Human Services Department. (2000). PHS policy for instruction in the responsible conduct of research; availability of new draft, Retrieved June 3, 2021, from https://grants.nih.gov/grants/guide/notice-files/ not-od-10-019.html

Hendrickson, T. L. (2015). Integrating responsible conduct of research education into undergraduate biochemistry and molecular biology laboratory curricula. Biochemistry and Molecular Biology Education, 43(2), $68-$ 75. doi: 10.1002/bmb.20857
Hensel, N. (2018). Course-based undergraduate research: Educational equity and high-impact practice (1st ed.). Sterling, VA: Stylus Publishing.

Jordan, T. C., Burnett, S. H., Carson, S., Caruso, S. M., Clase, K., DeJong, R. J., ... \& Hatfull, G. F. (2014). A broadly implementable research course in phage discovery and genomics for first-year undergraduate students. MBio, 5(1), e01051-13. doi: 10.1128/mBio.01051-13

Lynch, D., \& Smith, R. (2011). Designing the classroom curriculum in the knowledge age. Brisbane, Australia: AACLM Press.

Marrs, K. A., \& Novak, G. (2004). Just-in-time teaching in biology: Creating an active learner classroom using the Internet. Cell Biology Education, 3(1), 49-61.

Mulhearn, T. J., Steele, L. M., Watts, L. L., Medeiros, K. E., Mumford, M. D., \& Connelly, S. (2017). Review of instructional approaches in ethics education. Science and Engineering Ethics, 23(3), 883-912. doi: 10.1007/ s11948-016-9803-0

National Academy of Sciences. (2009). On being a scientist: A guide to responsible conduct in research (3rd ed.). Washington, DC: National Academies Press. https://doi.org/10.17226/12192

National Health and Medical Research Council. (2018). Australian Code for the Responsible Conduct of Research. Retrieved August 20, 2020, from https://nhmrc.gov.au/about-us/publications/australian-code-responsible -conduct-research-2018

National Institutes of Health (NIH). (1989). Requirement for programs on the responsible conduct of research in national research service award institutional training programs. NIH Guide, 18(45), 1.

NIH. (2009). NOT-OD-10-019: Update on the requirement for instruction in the responsible conduct of research. Retrieved February 22, 2019, from https://grants.nih.gov/grants/guide/notice-files/not-od-10-019.html

Olimpo, J. T., Diaz-Martinez, L. A., Bhatt, J. M., \& D'Arcy, C. E. (2017). Integration of RCR and ethics education into course-based undergraduate research experiences in the biological sciences: A needed discussion. Journal of Microbiology \& Biology Education, 18(2). doi: 10.1128/jmbe. $\mathrm{v} 18 \mathrm{i} 2.1344$

Olimpo, J. T., Fisher, G. R., \& DeChenne-Peters, S. E. (2016). Development and evaluation of the Tigriopus course-based undergraduate research experience: Impacts on students' content knowledge, attitudes, and motivation in a majors introductory biology course. CBE-Life Sciences Education, 15(4), ar72. doi: 10.1187/cbe.15-11-0228

Phillips, T., Nestor, F., Beach, G., \& Heitman, E. (2018). America COMPETES at 5 years: An analysis of research-intensive universities' RCR training plans. Science and Engineering Ethics, 24(1), 227-249. doi: 10.1007/s11948017-9883-5

Resnik, D. B., \& Dinse, G. E. (2012). Do U.S. research institutions meet or exceed federal mandates for instruction in responsible conduct of research? A national survey. Academic Medicine, 87, 1237-1242.

Resnik, D. B., \& Shamoo, A. E. (2011). The Singapore Statement on research integrity. Accountability in Research, 18(2), 71-75. doi: 10.1080/ 08989621.2011 .557296

Rodenbusch, S. E., Hernandez, P. R., Simmons, S. L., \& Dolan, E. L. (2016). Early engagement in course-based research increases graduation rates and completion of science, engineering, and mathematics degrees.CBELife Sciences Education, 15(2), ar20. doi: 10.1187/cbe.16-03-0117

Sarmah, S., Chism, G. W., Vaughan, M. A., Muralidharan, P., Marrs, J. A., \& Marrs, K. A. (2016). Using zebrafish to implement a course-based undergraduate research experience to study teratogenesis in two biology laboratory courses. Zebrafish, 13(4), 293-304. doi: 10.1089/zeb.2015.1107

Schussler, E. E., Read, Q., Marbach-Ad, G., Miller, K., \& Ferzli, M. (2015). Preparing biology graduate teaching assistants for their role as instructors: An assessment of institutional approaches. CBE-Life Sciences Education, 14(3), ar31.

Senchina, D. S. (2011). Video laboratories for the teaching and learning of professional ethics in exercise physiology curricula. Advances in Physiology Education, 35(3), 264-269. doi: 10.1152/advan.00122.2010

Shaffer, C. D., Alvarez, C., Bailey, C., Barnard, D., Bhalla, S., Chandrasekaran, C., ... \& Elgin, S. C. R. (2010). The Genomics Education Partnership: Successful integration of research into laboratory classes at a diverse group of undergraduate institutions. CBE-Life Sciences Education, 9(1), 55-69. doi: 10.1187/09-11-0087 
Shaffer, C. D., Alvarez, C. J., Bednarski, A. E., Dunbar, D., Goodman, A. L., Reinke, C., ... \& Elgin, S. C. R. (2014). A course-based research experience: How benefits change with increased investment in instructional time. CBE-Life Sciences Education, 13(1), 111-130. doi: 10.1187/cbe-13-08 $-0152$

Shapiro, C., Moberg-Parker, J., Toma, S., Ayon, C., Zimmerman, H., Roth-Johnson, E. A., ... \& Sanders, E. R. (2015). Comparing the impact of course-based and apprentice-based research experiences in a life science laboratory curriculum. Journal of Microbiology \& Biology Education, 16(2), 186-197. doi: 10.1128/jmbe.v16i2.1045

Shortlidge, E. E., Bangera, G., \& Brownell, S. E. (2016). Faculty perspectives on developing and teaching course-based undergraduate research experiences. BioScience, 66, 54-62. doi: 10.1093/biosci/biv167

Small World Initiative. (2020). Home page. Retrieved August 8, 2020, from www.smallworldinitiative.org/

Smith, E. M., Stein, M. M., \& Holmes, N. G. (2020). How expectations of confirmation influence students' experimentation decisions in introductory labs. Physical Review Physics Education Research, 16(1), 010113. doi: 10.1103/PhysRevPhysEducRes.16.010113

Steele, L. M., Mulhearn, T. J., Medeiros, K. E., Watts, L. L., Connelly, S., \& Mumford, M. D. (2016). How do we know what works? A review and critique of current practices in ethics training evaluation. Accountability in Research, 23(6), 319-350. doi: 10.1080/08989621.2016.1186547

Stein, M. M., Smith, E. M., \& Holmes, N. G. (2018). Confirming what we know: Understanding questionable research practices in intro phys ics labs. Retrieved June 2, 2021, from https://arxiv.org/pdf/1807.04716 .pdf

Steneck, N. H., \& Bulger, R. E. (2007). The history, purpose, and future of instruction in the responsible conduct of research. Academic Medicine, 82(9), 829-834. doi: 10.1097/ACM.0b013e31812f7d4d

Swanson, H. I., Sarge, O.-K. P., Rodrigo-Peiris, T., Xiang, L., \& Cassone, V. M. (2016). Development of a course-based undergraduate research experience to introduce drug-receptor concepts. Journal of Medical Education and Curricular Development, 3. doi: 10.4137/JMECD.S31233

Tesch, R. (2013). Qualitative research: Analysis types and software. New York, NY: Routledge.

Tiny Earth. (2020). Home page. Retrieved August 20, 2020, from https:// tinyearth.wisc.edu/

Turrens, J. F., \& Springer, M. S. (2019). How to train undergraduates in research integrity and the responsible conduct of research. Washington, DC: Council on Undergraduate Research.

Universities UK. (2012). The concordat to support research integrity. Retrieved August 20, 2020, from www.universitiesuk.ac.uk/policy-and -analysis/reports/Documents/2012/the-concordat-to-support -research-integrity.pdf

Wahila, M. J., Amey-Proper, J., Jones, W. E., Stamp, N., \& Piper, L. F. J. (2017) Teaching advanced science concepts through Freshman Research Immersion. European Journal of Physics, 38(2), 025704. doi: 10.1088/13616404/aa5959

Ward, J. R., Clarke, H. D., \& Horton, J. L. (2014). Effects of a research-infused botanical curriculum on undergraduates' content knowledge, STEM competencies, and attitudes toward plant sciences. CBE-Life Sciences Education, 13(3), 387-396. doi: 10.1187/cbe.13-12-0231

Watts, L. L., Medeiros, K. E., Mulhearn, T. J., Steele, L. M., Connelly, S., \& Mumford, M. D. (2017). Are ethics training programs improving? A meta-analytic review of past and present ethics instruction in the sciences. Ethics \& Behavior, 27(5), 351-384. doi: 10.1080/10508422.2016.1182025

Watts, L. L., Mulhearn, T. J., Medeiros, K. E., Steele, L. M., Connelly, S., \& Mumford, M. D. (2017). Modeling the instructional effectiveness of responsible conduct of research education: A meta-analytic path-analysis. Ethics \& Behavior, 27(8), 632-650. doi: 10.1080/10508422.2016.1247354

Wei, C. A., \& Woodin, T. (2011). Undergraduate research experiences in biology: Alternatives to the apprenticeship model. CBE-Life Sciences Education, 10(2), 123-131. doi: 10.1187/cbe.11-03-0028 